\title{
DESEMPENHO DE PROGÊNIES DE AÇAIZEIROS PROVENIENTES DE DUAS PROCEDÊNCIAS AVALIADAS PELO GRÁFICO DE CAIXA
}

\author{
Gilberto Ken-Iti Yokomizoㄹ, George Reis dos Santos², Renan Gomes Furtado², Ancelma Pereira \\ Brandão $^{3}$, Irecê Bezerra Colares ${ }^{3}$ \\ ${ }^{1}$ Embrapa Amapá, PPGDR da UNIFAP e BIONORTE do MCT. Endereço: Rodovia Juscelino Kubitschek, 2600, Caixa Postal 10, \\ CEP 68906-970, Macapá - AP. Email: gilberto@cpafap.embrapa.br \\ ${ }^{2}$ Engenheiro Florestal, IMMES - Instituto Macapaense do Melhor Ensino Superior \\ ${ }^{3}$ Gerente Ambiental, FAMA - Faculdade de Macapá
}

\section{RESUMO}

Um importante componente da dieta alimentar dos habitantes ribeirinhos e nas cidades do Amapá e Pará é o açaí, havendo também o interesse em outras regiões e países. São, portanto, importantes as pesquisas visando seleção de materiais superiores para suprir a crescente demanda de consumo. No presente estudo foram comparadas, no campo experimental de Mazagão, da Embrapa Amapá, 75 progênies da região do município do Afuá, PA com 100 progênies da região leste da ilha de Marajó, PA. O experimento foi instalado em blocos ao acaso com duas repetições, sendo avaliados os caracteres: quantidade de estipes adultas, quantidade de estipes jovens, quantidade de rebentos, altura de planta adulta, altura de planta jovem, circunferência do estipe mais velho, circunferência média das estipes jovens, número de cachos, comprimento do entrenó e quantidade de folhas. Os resultados indicaram desempenhos diferentes entre as procedências para todos os caracteres avaliados. As procedências oriundas do Afuá apresentaram valores superiores às do Marajó, excetuando-se apenas a quantidade de rebentos. O número de folhas foi o único caráter que não apresentou diferenças. Foram observados valores nos extremos dos gráficos de caixa que apresentam progênies com potencial para serem selecionadas. O gráfico de caixa demonstrou ser um instrumento eficiente para distinguir as duas procedências.

Palavras-chave: Euterpe oleracea, melhoramento genético, Amazônia, parâmetros genéticos

\section{PERFORMANCE OF THE ASSAI PALM PROGENIES FROM TWO PROVENANCES EVALUATED BY THE BOX PLOT}

\begin{abstract}
The assai fruit is an important component of the feeding diet of the riverside and city inhabitants of the States of Amapá and Pará, Brazil. Therefore the researches are important for the selection of materials to supply the increasing consumption demand. In the present study there were compared, in the experimental field of Mazagão, belonging to Embrapa Amapá, 75 progenies of the municipal district of Afuá, PA, with 100 progenies of eastern island of Marajó, PA. The experiment was installed in randomized blocks with two repetitions, and the following characters were evaluated: amount of the adult stipes; amount of the young stipes; amount of the sprouts; height of the adult plant; height of the young plant; circumference of the oldest stipe; mean circumference of the young estipes; total number of bunches; length of internode and number of leaves. The results indicated different performances among the provenances for all the evaluated characters. The provenances from Afuá showed higher values than those from Marajó,
\end{abstract}


excepting the number of sprouts. The number of leaves was the only character that did not present differences. Values were observed in the limits of box plots showing progenies with potential to selection. The box plot proved to be an efficient tool to distinguish the two provenances.

Keywords: Euterpe oleracea, genetic breeding, Amazon, genetic parameters

\section{INTRODUÇÃO}

O açaizeiro (Euterpe oleracea Mart.) é uma palmeira nativa da Região Amazônica encontrada nas várzeas do estuário amazônico, onde possui elevada importância socioeconômica. O estado do Pará é atualmente o maior produtor de frutos e o principal consumidor da polpa extraída por meio da maceração manual ou mecânica cuja denominação regional é "açaí". A comercialização é feita in natura e congelada para atender o mercado local e, mais recentemente, em nível nacional para a fabricação de sorvetes, picolés, bebidas energéticas e como complemento e/ou substituto das principais refeições (Oliveira et al., 2002). O fruto possui bom valor nutricional e constitui-se numa das bases alimentares da dieta das populações dos Estados do Pará e Amapá. Sua composição é caracterizada por um elevado teor de lipídios, proteínas, fibras e antocianinas.

Na região Sul do Brasil, o consumo é crescente, tendo entre seus atrativos o fato de ser um alimento com apelo ecológico devido a origem Amazônica e por ser considerado energético (Rogez, 2000). Essas propriedades sugerem excelentes oportunidades comerciais para a exportação da polpa, inclusive para os mercados com elevado poder aquisitivo do Hemisfério Norte, sendo observado um crescimento anual com taxas superiores a $30 \%$ da venda de polpa congelada para outros estados brasileiros, podendo chegar à cerca de $10 \mathrm{mil}$ toneladas anuais, além das quase mil toneladas exportadas anualmente para vários países na forma de mix ou em mistura, principalmente do açaí e guaraná (Farias Neto et al., 2005).

Esses fatos têm motivado a implantação do cultivo de açaizais em terra firme (Queiroz \& Mochiutti, 2001). Entretanto, a expansão dos cultivos nestes locais tem apresentado resultados altamente heterogêneos quanto à produtividade $\mathrm{e}$ qualidade dos frutos, principalmente em decorrência da falta de materiais genéticos portadores de bons caracteres agronômicos para estas novas condições e da umidade menor do que no ambiente natural de ocorrência da espécie. Existindo apenas um material selecionado e disponibilizado pela Embrapa Amazônia Oriental (Belém) para comercialização denominada de BRS Pará. Devendo-se observar nos processos de seleção o desenvolvimento vegetativo da planta que poderá refletir posteriormente em estruturas mais adequadas para a sustentação de cachos maiores ou em maiores quantidades e melhor adaptabilidade em ambiente com menor umidade.

O açaizeiro é uma espécie perene, alógama e propagada ainda quase que exclusivamente por sementes (Jardim \& Macambira 1996; Oliveira et al., 2000), estando ainda na etapa denominada de semidomesticação ou em fase de domesticação (Clement, 1992). O açaizeiro produz descendentes geneticamente idênticos ao indivíduo original pelo processo de perfilhamento. Entretanto, sua variabilidade genética é garantida pela reprodução sexual (Ohashi \& Kageyama, 2004). Essa variabilidade genética é fundamental na seleção de materiais superiores, quando se objetiva sucesso na 
condução de programas de melhoramento genético e, pode ser possivelmente mais intensa entre populações. Sendo assim, é de grande importância o conhecimento sobre o sistema de cruzamento, a variabilidade genética disponível entre diferentes populações, a herança qualitativa ou quantitativa dos caracteres e o potencial agronômico dos genótipos. Nessas condições, pode-se impor um processo seletivo que venha resultar em ganhos genéticos, o que torna viável e exeqüível o melhoramento genético (Allard, 2001).

Diferenças genéticas entre populações/procedências e/ou progênies têm sido detectadas para vários caracteres avaliados, indicando a possibilidade na seleção de materiais superiores no melhoramento genético em açaizeiro e também subsidiando estratégias de coletas de sementes de populações naturais visando à conservação ex situ, segundo Oliveira et al. (2000), Farias Neto et al. (2003) e Ohashi \& Kageyama (2004).

Desta forma o objetivo deste trabalho foi verificar a existência de diferenças existentes entre duas procedências e suas progênies com relação aos caracteres vegetativos e de produção, através do uso dos gráficos de caixa (Box-plot).

\section{MATERIAL E MÉTODOS}

Foram avaliadas 175 progênies, sendo 100 progênies procedentes da região leste da Ilha de Marajó e 75 procedente das proximidades do município de Afuá, ambas localizadas no Estado do Pará. As progênies foram avaliadas no Campo Experimental de Mazagão, Estado do Amapá, em área de várzea, pertencente a Embrapa Amapá, em solo predominante do tipo Gley, pouco húmico de textura média, drenado e de média-alta fertilidade natural. No período das avaliações as progênies apresentavam seis anos de idade. A área experimental localiza-se nas coordenadas $00^{\circ} 02$ ' 33 " de latitude sul e $51^{\circ} 15^{\prime} 24^{\prime \prime}$ longitude oeste, a 15 $\mathrm{m}$ altitude, com topografia plana e cobertura vegetal tipo capoeira. Sendo do tipo climático Ami, segundo a classificação de Köppen, caracterizando-se por ser tropical chuvoso, com temperatura média do mês mais frio não inferior a $22,5^{\circ} \mathrm{C}$ e com precipitação do mês mais seco de $10 \mathrm{~mm}$. A precipitação média anual encontra-se próximo de $2.300 \mathrm{~mm}$, havendo concentração entre os meses de janeiro a junho, sendo a temperatura média anual de $28^{\circ} \mathrm{C}$ e umidade média do ar de $85 \%$.

O teste das progênies foi instalado em delineamento de blocos ao acaso com 175 progênies, duas repetições e parcelas de cinco plantas, sendo utilizada as médias das plantas. $\mathrm{O}$ espaçamento entre plantas foi de 4 m x 5 m (500 plantas/ha).

Foram avaliados os seguintes caracteres, com adaptações na nomenclatura proposta por Oliveira et al. (2006): QTA: número de estipes adultas com vestígios ou presença de frutificação presente na touceira; QTJ: número de estipes jovens próximas da frutificação mas sem presença de vestígios de frutificação anterior presentes na touceira; QTR: número de estipes com menos de 1,50m de altura presentes na touceira; APA: altura de uma planta adulta representativa da média das adultas presentes na touceira, medida em metros; APJ: altura de uma planta jovem representativa da média das jovens presentes na touceira, medida em metros; CAP: circunferência do estipe mais velho da touceira, na altura de $1,30 \mathrm{~m}$ a partir do solo, medida em centímetros; CAJ: circunferência da estipe representativa da média das estipes jovens da touceira, na altura de 1,30m a partir do solo, medida em centímetros; NTC: número de cachos produzidos durante os anos de produção, através da contagem de cicatrizes indicativas de desenvolvimento de cachos em anos 
anteriores; CEN: comprimento de um entrenó localizado à $1,30 \mathrm{~m}$ a partir do solo, utilizando-se a média das cinco plantas da parcela, em centímetros e; NF: número de folhas existente na estipe mais velha da touceira.

A análise de variância foi realizada com o intuito de verificar eventuais diferenças entre as progênies das procedências e entre as procedências, para os caracteres avaliados, com auxílio do programa SAS (SAS INSTITUTE, 2000) e GENES (Cruz, 2006).

O modelo estatístico adotado para a análise de variância segundo Vencovsky e Barriga (1992) foi: $Y i j=m+G i+P j+e i j$; em que : Yij é o valor fenotípico médio do caráter $\mathrm{Y}$ medido no material genético $\mathrm{i}$, na procedência j; $m$ é a média geral paramétrica dos dados em estudo; Gi é o efeito da iésima progênie; $\mathrm{Pj}$ : é o efeito da j-ésima procedência; eij é o erro médio associado à observação Yij.

Considerou-se como aleatório o efeito das progênies avaliadas, pois não houve qualquer controle de polinização para se obter as mesmas, podendo ser consideradas como representativas das procedências originais.

Nos caracteres em que foram detectadas diferenças significativas entre as populações/procedências foi aplicado o gráfico de caixa ou Box-plot, que é um dispositivo que permite a visualização da diferenças baseado nas estimativas das separatrizes, que são a mediana (md) e os quartis (Qi) (Iemma, 1992a; 1992b).

A mediana corresponde ao ponto que divide os dados em duas metades iguais (50\%) da distribuição e é estimada segundo a equação: $\mathrm{md}=\mathrm{l}_{\mathrm{md}}+\frac{\left(\mathrm{n} / 2-\mathrm{F}_{\mathrm{ant}}\right)}{\mathrm{f}_{\mathrm{md}}} \cdot \mathrm{a}_{\mathrm{md}}$

Sendo: $1_{\mathbf{m d}}$ : limite inferior da classe mediana; $\mathrm{F}_{\text {ant }}$ : frequência acumulada da classe anterior à classe mediana (valor acumulado); $\mathrm{f}_{\mathbf{m d}}$ : frequência absoluta simples da classe mediana (valor do número de dados observados); $\mathrm{a}_{\text {md }}$ : amplitude da classe mediana (subtração entre $o$ valor máximo e mínimo da classe).

Os quartis representam porcentagens dos dados, sendo que o primeiro quartil $\left(\mathrm{Q}_{1}\right)$ envolve $25 \%$ dos dados e o terceiro quartil $\left(\mathrm{Q}_{3}\right)$ envolve $75 \%$, e representados pelas equações: $\mathrm{Q}_{1}=\mathrm{l}_{\mathrm{Q}_{1}}+\frac{\left(\mathrm{n} / 4-\mathrm{F}_{\mathrm{ant}}\right)}{\mathrm{f}_{\mathrm{Q}_{1}}} \mathrm{a} \quad \mathrm{e}$; $\mathrm{Q}_{3}=\mathrm{l}_{\mathrm{Q}_{3}}+\frac{\left(3 \mathrm{n} / 4-\mathrm{F}_{\mathrm{ant}}\right)}{\mathrm{f}_{\mathrm{Q}_{3}}} \mathrm{a}$

Sendo: $1_{\mathbf{Q} 1}$ e $1_{\mathbf{Q} 3}$ : limites inferiores das classes que contém o primeiro quartil $\left(\mathrm{Q}_{1}\right)$ e o terceiro $\left(\mathrm{Q}_{3}\right)$; $\mathrm{F}_{\text {ant: }}$ frequência acumulada da classe anterior à classe que contém o quartil que está sendo estimado; $f_{Q_{1}}$ e $f_{Q_{3}}$ : frequências absolutas simples das classes que contém os quartis; a: amplitude da classe do quartil que está sendo estimado.

Após as estimativas da mediana e dos quartis, o gráfico de caixa é esquematizado conforme:

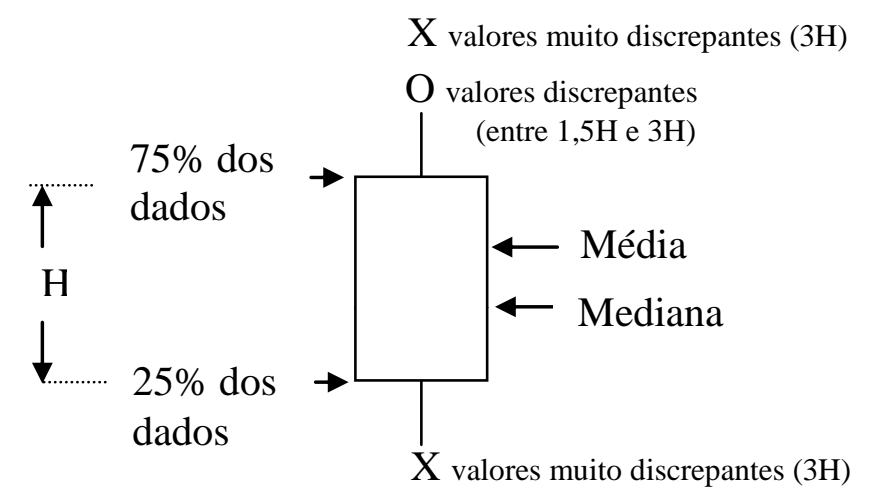

As medianas com valores menores que a média indicam a existência de assimetria positiva, enquanto que as medianas menores que a média correspondem à assimetria negativa.

Valores discrepantes são os valores que apresentam médias bem diferentes em relação à média dos demais tratamentos, mas 
que podem ser considerados aceitáveis. Os valores muito discrepantes são valores extremamente diferentes em relação aos demais e devem ser estudados com maior cuidado.

A construção de gráficos de caixa permite verificar de forma simples e rápida se há distinção do comportamento geral entre as procedências e de suas progênies.

\section{RESULTADOS E DISCUSSÃO}

O resumo da análise de variância e a significância para o teste $\mathrm{F}$ apresentado na Tabela 1, permitem observar a presença de diferenças significativas entre as duas procedências para todos os caracteres avaliados. Uma única exceção ocorreu para o caráter QTJ onde apesar da diferença entre as progênies não houve distinção entre as procedências. Sendo que para o caráter quantidade de perfilhos e circunferência da estipe, comparando materiais de origem distintas, Farias Neto et al. (2005) também conseguiram observar a presença de diferenças significativas a $5 \%$ de probabilidade. Para o caráter NF o resultado foi semelhante ao obtido por Farias Neto et al. (2003) com variação entre as populações e distinto de Farias Neto et al. (2005), que não observou variação para este mesmo caráter entre as diferentes populações avaliadas. Para CAP não foram observadas diferenças no trabalho de Farias Neto et al. (2003). A presença da significância entre os caracteres para procedências é interessante para o processo de melhoramento genético pois garante a existência de variabilidade necessária para a seleção de materiais superiores e demonstra que há diferenças entre as procedências.

As médias para os caracteres relacionados à número de rebentos, estipes jovens e adultas revelaram que há tendência de progênies pertencentes as procedências de apresentarem menor quantitativo conforme existe o desenvolvimento da touceira (QTA, QTJ e QTR), demonstrando que inicialmente há grande produção de perfilhos e com o estabelecimento definitivo há menor emissão. Existindo algumas que mantiveram a produção elevada de rebentos, mantendo com isso número o quantitativo de indivíduos presentes na touceira sempre alto. Os valores aqui obtidos para QTA, QTJ e QTR foram inferiores aos citados por Oliveira et al. (2007), sendo que também para o comprimento do entrenó (CEN) os valores foram muito inferiores, havendo como possível explicação as condições ambientais oferecidas em Mazagão para o crescimento anual das estipes e a genética responsável pelo controle da características serem distintos entre os trabalhos, devido a origem diferente das procedências. O CV envolvendo a quantidade de indivíduos adultos, jovens e rebentos foi elevado, exibindo valores entre $56,270 \%$ e $60,909 \%$, demonstrando haver elevada variabilidade entre as diferentes progênies que compõem as procedências e, portanto oferecendo oportunidades de seleção de materiais superiores com facilidade.

Considerando a altura da estipe adulta e NF, os resultados apresentaram-se maiores em relação ao observado por Oliveira et al. (2007), enquanto que para $\mathrm{CAP}$ e CEN foram inferiores. $\mathrm{Na}$ comparação com os resultados obtidos por Farias Neto et al. (2003) e Farias Neto et al. (2005) para os caracteres APA, CAP, NF e QTR e QTJ, as estimativas foram superiores. Essa grande variabilidade verificada pode ser reflexo da variabilidade naturalmente existente em populações naturais onde o processo de domesticação não foi efetuado. Para os caracteres em que foram observadas diferenças significativas pelo teste $\mathrm{F}$ nas procedências compostas pelas progênies, torna-se importante a realização de uma análise que permita a distinção das mesmas. 
Tabela 1. Resumo da análise de variância de 175 progênies de açaizeiro (Euterpe oleracea) de duas procedências (Afuá e Marajó) para dez caracteres, aos seis anos de idade.

\begin{tabular}{|c|c|c|c|c|c|c|c|c|c|c|c|}
\hline & G.L & QTA & QTJ & QTR & APA & APJ & CAP & CAJ & NCA & CEN & NF \\
\hline Prog & 173 & $0,226 \mathrm{~ns}$ & $0,694 *$ & $2,769 * *$ & $0,675 \mathrm{~ns}$ & $0,337 \mathrm{~ns}$ & $22,008 *$ & $7,131 \mathrm{~ns}$ & $1,048 \mathrm{~ns}$ & $2,439 \mathrm{~ns}$ & $1,923 \mathrm{~ns}$ \\
\hline $\begin{array}{l}\text { Pop } \\
\text { Erro }\end{array}$ & $\begin{array}{l}1 \\
175\end{array}$ & $\begin{array}{l}2,746^{* * *} \\
0,318\end{array}$ & $\begin{array}{l}0,195^{\mathrm{ns}} \\
0,513\end{array}$ & $\begin{array}{l}90,112 * * \\
1,500\end{array}$ & $\begin{array}{l}135,122 * * \\
0,630\end{array}$ & $\begin{array}{l}29,933 * * \\
0,356\end{array}$ & $\begin{array}{l}4958,986^{* *} \\
16,553\end{array}$ & $\begin{array}{l}1195,529 * * \\
7,526\end{array}$ & $\begin{array}{l}34,033 * * \\
1,024\end{array}$ & $\begin{array}{l}291,468 * * \\
2,173\end{array}$ & $\begin{array}{l}21,615^{* * *} \\
1,562\end{array}$ \\
\hline Total & 349 & & & & & & & & & & \\
\hline & $\begin{array}{l}\mathrm{CV}^{\mathrm{b}} \\
\text { Média }\end{array}$ & $\begin{array}{l}57,888 \\
0,974\end{array}$ & $\begin{array}{l}60,909 \\
1,175\end{array}$ & $\begin{array}{l}56,270 \\
2,177\end{array}$ & $\begin{array}{l}15,352 \\
5,169\end{array}$ & $\begin{array}{l}21,533 \\
2,771\end{array}$ & $\begin{array}{l}12,862 \\
31,631\end{array}$ & $\begin{array}{l}12,924 \\
21,226\end{array}$ & $\begin{array}{l}28,694 \\
3,526\end{array}$ & $\begin{array}{l}12,168 \\
12,114\end{array}$ & $\begin{array}{l}12,193 \\
10,250\end{array}$ \\
\hline
\end{tabular}

**: significativo a 5\% para o teste $\mathrm{F}$; ns: não significativo para o teste $\mathrm{F}$

${ }^{a}$ QTA, quantidade de estipes adultas; QTJ: quantidade de estipes jovens; QTR: quantidade de rebentos; APA: altura de planta adulta; APJ: altura de planta jovem; CAP: circunferência do estipe mais velho; CAJ: circunferência da estipe representativa da média das estipes jovens; NTC: número de cachos; CEN: comprimento do entrenó e; NF: quantidade de folhas.

${ }^{\mathrm{b}} \mathrm{CV} \%$ : coeficiente de variação experimental em porcentagem.

Neste trabalho decidiu-se utilizar o gráfico de caixa ou Box Plot para distinguir duas procedências compostas por diferentes progênies, sendo que este procedimento é interessante para se comparar dados de dois ou mais grupos, colocando-os lado a lado (Montgomery, 1991a; 1991b; Lane, 2011) e, com isso observar o comportamento dos genótipos para os caracteres avaliados em cada população de açaizeiro. De acordo com Rose (1994) este gráfico permite a visualização da distribuição geral dos dados, sua média e sua mediana (valor que divide a distribuição em duas metades de dados), permitindo a realização de inferências sobre o comportamento entre as procedências avaliadas.

Desta forma na Figura 1, em que estão associados os caracteres relativos à quantidade de estipes nas diferentes fases de desenvolvimento da planta, observa-se que as procedências do Marajó apresentaram maior quantidade de rebentos em relação a do Afuá e conforme ocorre a maturidade da touceira há aparente inversão de comportamento. Com isso as procedências do Marajó tendem a produzir maior número de estipes iniciais, mas com elevadas perdas comparativamente com as do Afuá, sendo que na fase adulta (QTA) os limites superiores são semelhantes, mas no geral (limites englobando 25 a $75 \%$ das progênies) as procedências do Afuá tendem a apresentar maior número de estipes adultas, mas com pouca superioridade conforme pode ser observado pelos limites e dimensões das "caixas".

São preferidos valores menores para o caráter altura dos estipes das plantas, visando obter indivíduos mais baixos para facilitar o processo de colheita dos cachos. $\mathrm{Na}$ Figura 2, as procedências do Afuá apresentaram plantas mais altas tanto na fase jovem como na adulta. Sendo que na fase adulta o comportamento em altura do material do Afuá é superior ao exibido pela do Marajó. Desta forma, baseado nos gráficos de caixa observados na Figura 2, pode-se notar que as procedências originadas do Marajó tiveram no geral resultados mais interessantes por conter plantas mais baixas. Farias Neto et al. (2003) comparando populações distintas não conseguiram detectar diferenças, citando que a origem das populações pode conter diferentes variabilidades genéticas, principalmente entre indivíduos da mesma progênie.

Existem indicativos da presença de plantas adultas em ambas as procedências com porte menor, com valor mínimo de 3,6 e 2,8 m nas do Afuá e do Marajó, respectivamente, que podem ser selecionadas para este caráter, permitindo a formação de cachos em menores alturas e 
com isso ampliar o uso produtivo dos estipes.

Nos gráficos de caixa o caráter comprimento do entrenó (CEN) que representa $o$ processo de elongação do estipe, demonstra que as procedências do Afuá apresentaram elongações superiores em relação as da outra procedência, o que é indesejável, indicando crescimento anual em altura do estipe mais rápido, o que iria aumentar a dificuldade do processo de colheita com o passar do tempo e diminuiria o tempo de vida útil da touceira. Importante foi observar que o limite inferior foi semelhante entre as procedências com valores de 9,0 e $8,7 \mathrm{~cm}$, nas plantas com menores valores de CEN.

$\mathrm{Na}$ circunferência do estipe (CAP), tanto em plantas adultas, como nas jovens, houve comportamento semelhante ao observado para o caráter altura de estipe, com as procedências do Afuá apresentando maiores valores, tanto na fase jovem como também na adulta da touceira, comparativamente com as mesmas fases nas procedências do Marajó (Figura 3). Em estipes adultos o CAP das procedências oriundas do Afuá, no geral, teve $75 \%$ das progênies acima do limite superior do gráfico de caixa das procedências do Marajó.

Este comportamento indica que as plantas provenientes do Afuá possuem melhor desenvolvimento do estipe para a circunferência em relação às do Marajó. Porém este maior desenvolvimento da circunferência do estipe também pode ser reflexo da maior altura como pode ser observado na Figura 2. Deve-se buscar progênies em que se possa associar alturas menores com maiores circunferências, selecionando-se estipes mais baixas e com maior circunferência, obtendo-se melhor estrutura de sustentação física das plantas permitindo bom desenvolvimento vegetativo e reprodutivo.

Para as características produtivas, nas procedências do Afuá, pode se observar valores superiores para o caráter número de cachos (NCA) em relação às do Marajó. Porém, os limites inferiores e superiores das "caixas" que englobam $25 \%$ e $75 \%$ dos valores das duas procedências foram próximos, sendo que as do Afuá tiveram a distribuição das progênies menos dispersa, ou seja, as médias das diferentes progênies são mais semelhantes para esta população, enquanto que nas do Marajó foi observado variabilidade pouco superior comparativamente (Figura 4).

O caráter número de folhas viáveis (NFO) apresentou comportamento relativamente similar entre as duas procedências, ao se considerar os valores dentro dos limites de $25 \%$ e $75 \%$ das “caixas". A presença de alguns indivíduos com valores inferiores nas oriundas do Marajó demonstraram a existência de progênies com quantidades menores de folhas viáveis, em relação às do Afuá, podendo ser esta menor área fotossintética responsável pelos demais caracteres em que as procedências do Marajó tiveram menor desempenho. Apesar disso, há demonstração de que em termos de média este caráter comportou-se de forma semelhante entre as duas procedências, ocorrendo apenas maior dispersão dentro das progênies do Marajó, também observado pelo desempenho comparativo entre as populações avaliadas por Farias Neto et al. (2003). 

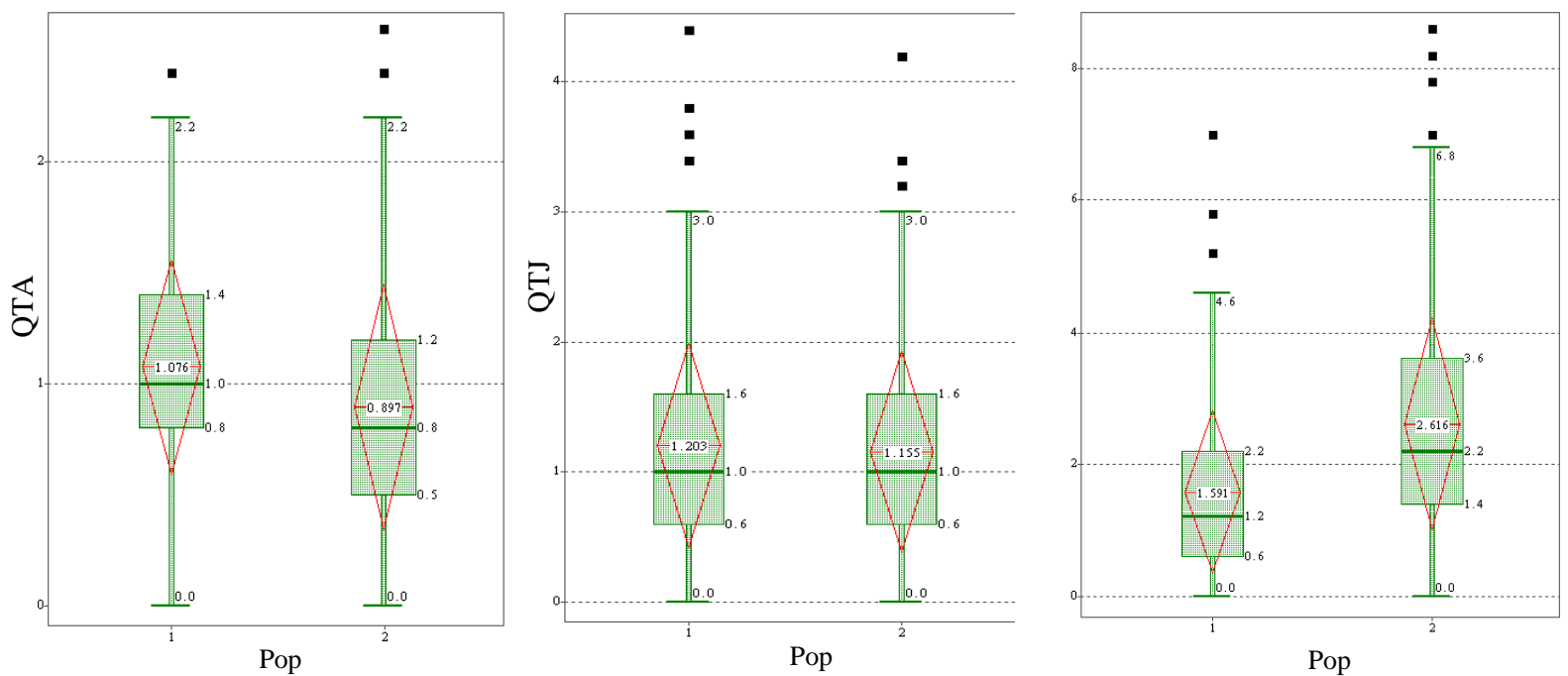

Figura 1. Gráficos de caixa (Box-plot) relativos aos caracteres número de estipes adultas (QTA), número de estipes jovens (QTJ) e número de rebentos (QTR) presentes nas touceiras de açaizeiros em progênies das procedências de Afuá (pop 1) e Marajó (pop 2).
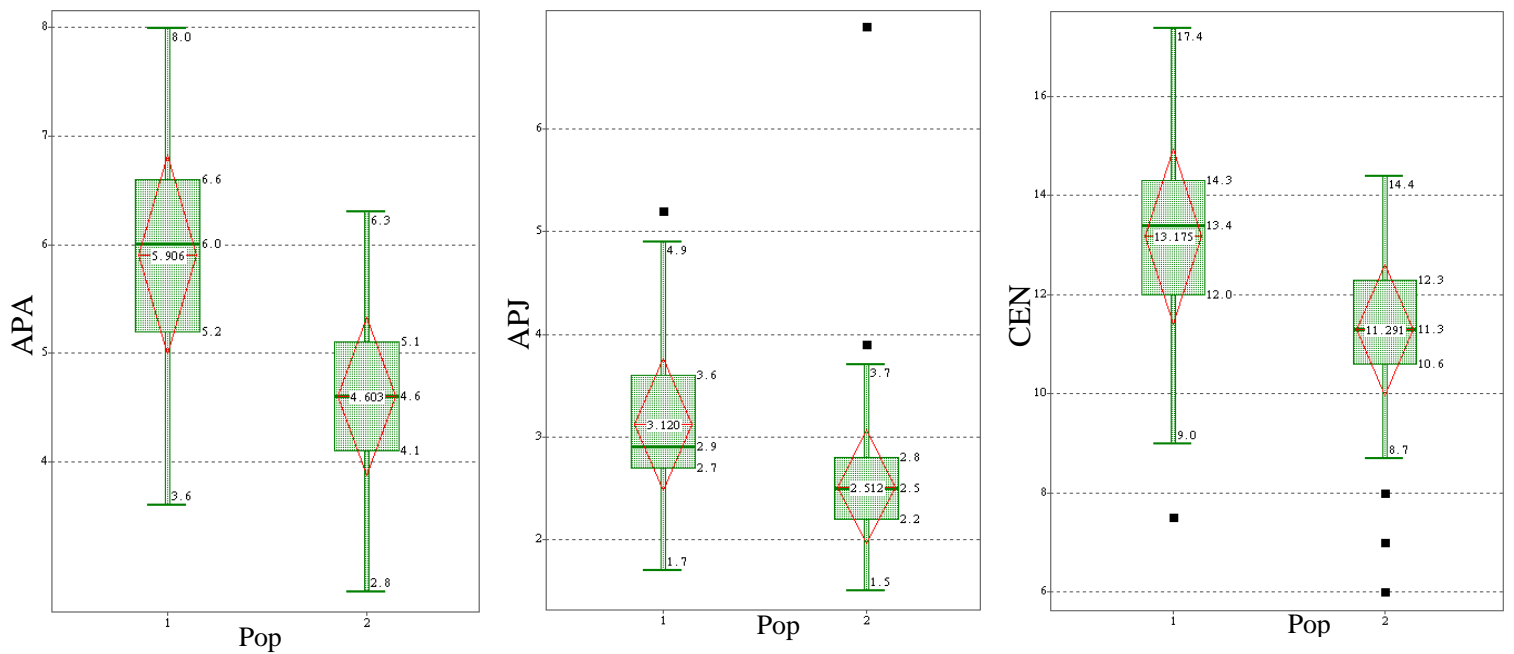

Figura 2. Gráficos de caixa (Box-plot) relativos aos caracteres de altura de estipes adultas (APA), das estipes jovens (APJ) presentes e comprimento do entrenó das estipes (CEN) nas touceiras de açaizeiros em progênies das procedências de Afuá (Pop 1) e Marajó (Pop 2). 

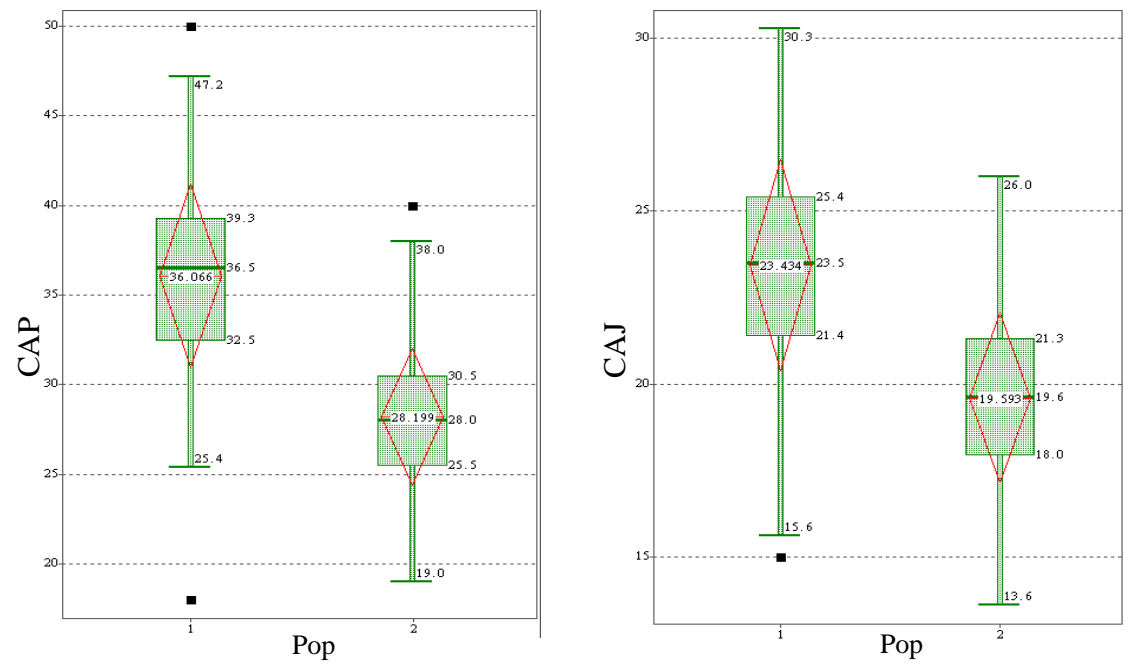

Figura 3. Gráficos de caixa (Box-plot) relativos aos caracteres de circunferência de estipes adultas (CAP) e das estipes jovens (CAJ) presentes nas touceiras de açaizeiros em progênies das procedências de Afuá (pop 1) e Marajó (Pop 2).
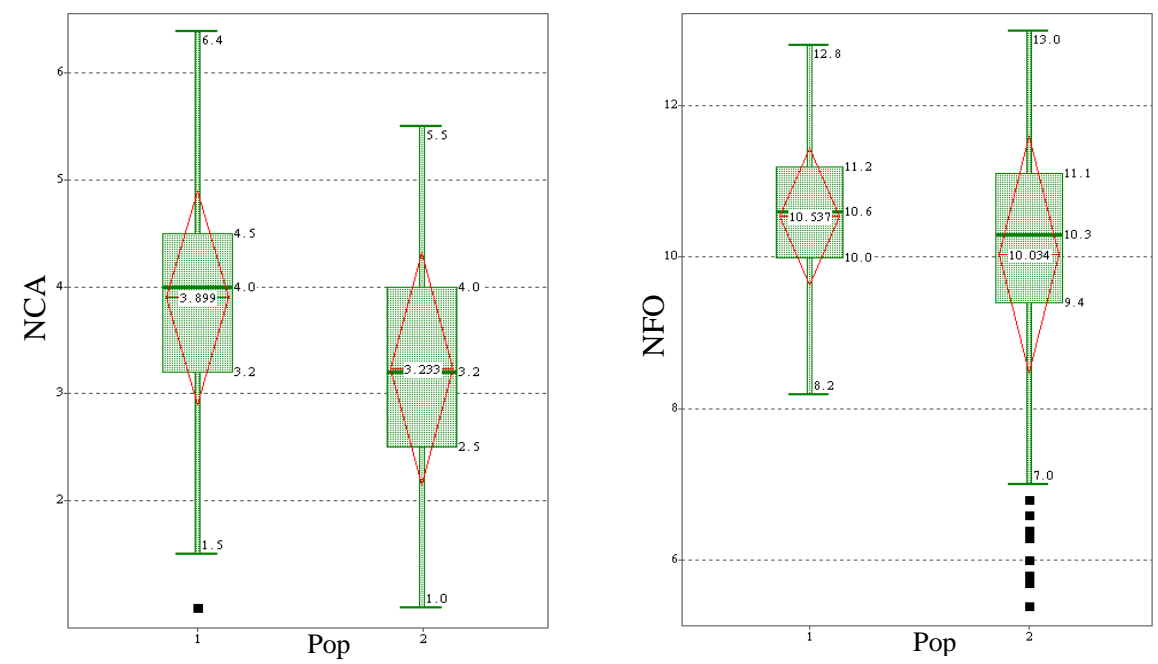

Figura 4. Gráficos de caixa (Box-plot) relativos aos caracteres de número de cachos com frutos (NCA) e número de folhas viáveis (NFO) presentes nas touceiras de açaizeiros em progênies das procedências de Afuá (pop 1) e Marajó (pop 2).

O caráter número de folhas viáveis (NFO) apresentou comportamento relativamente similar entre as duas procedências, ao se considerar os valores dentro dos limites de $25 \%$ e $75 \%$ das "caixas". A presença de alguns indivíduos com valores inferiores nas oriundas do Marajó demonstraram a existência de progênies com quantidades menores de folhas viáveis, em relação às do Afuá, podendo ser esta menor área fotossintética responsável pelos demais caracteres em que as procedências do Marajó tiveram menor desempenho. Apesar disso, há demonstração de que em termos de média este caráter comportou-se de forma semelhante entre as duas procedências, ocorrendo apenas maior dispersão dentro das progênies do Marajó, 
também observado pelo desempenho comparativo entre as populações avaliadas por Farias Neto et al. (2003).

\section{CONCLUSÕES}

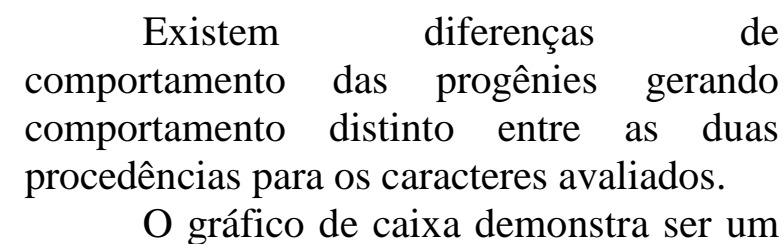
instrumento eficiente para distinguir as duas procedências;

Existem progênies com desempenho superior, indicando a possibilidade de seleção entre e dentro das procedências, considerando-se a seleção de progênies abaixo dos limites de $25 \%$ ou acima de $75 \%$ nos gráficos de caixa.

\section{AGRADECIMENTOS}

Os autores agradecem a Secretaria de Estado da Ciência e Tecnologia do Amapá (SETEC) em convênio com o Conselho Nacional de Ciência e Tecnologia (CNPq) pelas bolsas de iniciação concedidas.

\section{REFERÊNCIAS BIBLIOGRÁFICAS}

ALLARD, R. W. 2001. Principles of plant breeding. New York: John Wiley \& Sons Press, 264p.

CLEMENT, C. R. 1992. Domesticated palms. Principies, Lawrence, v.36, n.2, p.70-78.

CRUZ, C. D. 2006. Programa Genes: Biometria. Editora UFV. Viçosa (MG). 382p.

FARIAS NETO, J.T.; MULLER, A.A.; OLIVEIRA, M. S. P.; ESPIRITO SANTO, D. E.; SILVA, M. A. 2003. Variabilidade genética entre duas procedências de açaizeiro (Euterpe oleracea Martus). Boletim de Pesquisa Florestal, Colombo, v.46, p. 97-104.
FARIAS NETO, J. T; OLIVEIRA, M. S. P.; SANTOS, N. S. A.; MULLER, A. A.; NOGUEIRA, O. L.; ANAISSI, D. F. S. P. 2005. Variabilidade genética em progênies jovens de açaizeiro. Cerne, Lavras, v.11, n.4, p.336-341.

FARIAS NETO, J. T; RESENDE, M. D. V.; OLIVEIRA, M. S. P.; SANTOS, N. S. A.; CANUTO, E. L.; NOGUEIRA, O. L.; MULLER, A. A. 2007. Avaliação genética de progênies de polinização aberta de açaí (Euterpe oleracea) e estimativas de parâmetros genéticos. Cerne, Lavras, v.13, n.4, p.376-383.

IEMMA, A. F. 1992a. VI. Parâmetros que descrevem a posição ou a tendência central In: IEMMA A.F. (Ed.) Estatística descritiva. Piracicaba: $\varphi \sigma \rho$ publicações, cap.VI, p.87-107.

IEMMA, A. F. 1992b. VIII. Outros parâmetros e aplicações In: IEMMA A.F. (Ed.) Estatística descritiva. Piracicaba: $\varphi \sigma \rho$ publicações, cap.VIII, p.123-136.

JARDIM, M. A. G.; MACAMBIRA, M. L. J. 1996. Biologia floral do açaizeiro (Euterpe oleracea Martius). Boletim do Museu Paraense Emílio Goeldi. Série Botânica, Belém, v.12, n.1, p.131-136.

LANE, D. M. 2010. Describing Univariate Data. Disponível em : <http://davidmlane.com/hyperstat/desc_ univ.html> Acesso em 28/10/2011.

MONTGOMERY, D. C. 1991a. Simple comparative experiments In: Montgomery, D.C. (Ed.) Design and Analysis of Experiments $3^{\mathrm{a}}$ ed. John Wiley \& Sons Inc. Singapore, cap.2, p.14-49.

MONTGOMERY, D. C. 1991b. Experiments with a single factor: The analysis of variance In: Montgomery, D.C. (Ed.) Design and Analysis of Experiments $3^{\mathrm{a}}$ ed. John Wiley \& Sons Inc. Singapore, cap.3, p.50-94. 
OHASHI, S. T.; KAGEYAMA, P. Y. 2004. Variabilidade genética entre populações de açaizeiro (Euterpe oleracea Mart.) do estuário amazônico. In: MOURÃO, L.; JARDIM, M. A.; GROSSMANN, M. (Eds.) Açaí: possibilidade e limites em processos de desenvolvimento sustentável no estuário amazônico. Belém: CEJUP, p.11-26.

OLIVEIRA, M. S. P.; CARVALHO, J. E. U.; NASCIMENTO, W. M. O.; MÜLlER, C. H. 2002. Cultivo do açaizeiro visando a produção de frutos. Belém: Embrapa Amazônia Oriental, 51p. (Embrapa Amazônia Oriental. Circular técnica, 26).

OLIVEIRA, M. S. P.; FERREIRA, D. F.; SANTOS, J. B. 2006. Seleção de descritores para caracterização de germoplasma de açaizeiro para produção de frutos. Pesquisa Agropecuária Brasileira, Brasília, v.41, n.7, p.11331140.

OLIVEIRA, M. S. P.; LEMOS, M. A.; SANTOS, V. F.; SANTOS, E. O. 2000. Correlações fenotípicas entre caracteres vegetativos e de produção de frutos em açaizeiro. Revista Brasileira de Fruticultura, Jaboticabal, v.22, p.1-5.

OLIVEIRA, M. S. P.; FERREIRA, D. F.; SANTO, J. B. 2007. Divergência genética entre acessos de açaizeiro fundamentada em descritores morfoagronômicos. Pesquisa Agropecuária Brasileira, Brasília, v.42, n.4, p.501-506.

QUEIROZ, J. A. L.; MOCHIUTTI, S. 2001. Plantio de açaizeiros. Macapá: Embrapa Amapá, 8p. (Embrapa Amapá. Comunicado técnico, 55).

ROGEZ, H. 2000. Açaí: preparo, composição e melhoramento da conservação. 1.ed. Belém: Edufpa, $313 p$.

ROSE, S. 1994. Major ion variation and efflux related to discharge in a mafic Piedmont Province watershed.
Hydrological-Processes, v.8, n.5, p.481496.

SAS INSTITUTE (Cary, Estados Unidos). SAS language and procedures: usage. Version 8.1. Cary, NC, 2000. 1 CDROM

VENCOVSKY, R.; BARRIGA, P. 1992. Genética biométrica no fitomelhoramento. Ribeirão Preto: SBG, 496p. 